\section{Estudo \\ Ecidebate}

em Testão

Plamejamento
Revista Estudo \& Debate, Lajeado, v. 25, n. 3, 2018. ISSN 1983-036X

DOI: http://dx.doi.org/10.22410/issn.1983-036X.v25i3a2018.1856

\title{
GESTÁO DE EMPRESAS FAMILIARES: UM ESTUDO DE CASO EM UMA EMPRESA DE MATERIAIS DE CONSTRUÇÃO
}

\author{
Renata Mendes Heleno ${ }^{1}$, Wilson Ravelli Elizeu Maciel $^{2}$, Yasmin Gomes Casagranda ${ }^{3}$, \\ Arthur Caldeira Sanches ${ }^{4}$
}

\begin{abstract}
Resumo: Empresas consideradas familiares têm sua gestão ligada a um grupo de pessoas da mesma família e estão sujeitas aos ajustes e modificaçóes que o mercado exige para uma organização, bem como estấo sujeitas a problemas e ameaças próprios, que náo afetam apenas a empresa, mas a toda família a qual está vinculada. Este trabalho tem como objetivo analisar a gestáo de uma empresa familiar sob a ótica de bases conceituais presentes na literatura. É realizado um estudo de caso junto à empresa Construtelhas Comércio e Serviços Ltda. Para tanto, foi feita uma entrevista com o gestor da empresa, sendo os dados coletados analisados através do método de análise do conteúdo. Os resultados apontam que houve um aprimoramento no modelo de gestão adotada pela empresa, na qual o gestor e demais participantes utilizam os conhecimentos adquiridos em suas formaçōes, além de destacar a falta de conflitos oriundos de divergências entre a gestão familiar e não familiar que coexistem no mesmo ambiente de trabalho empresarial.
\end{abstract}

Palavras-chave: Empresa Familiar; Gestão; Desafios de gestão.

\section{FAMILY BUSINESS MANAGEMENT: A CASE STUDY AT A CONSTRUCTION MATERIALS COMPANY}

\begin{abstract}
Family businesses are those that have their management linked to a family, are subject to threats and changes that the market demands, and are also subject to problems and own threats that affect not only the company but the whole family that she is linked. This work aimed to analyze the management challenges present in a family business for your stay in the market. A case study was conducted by the company Construtelhas Comércio e Serviços Ltda. Therefore, an interview with the manager of the company was made, and the data collected analyzed using content analysis method. The results showed that there was an improvement in the management model adopted by the company, in which the manager and other participants use the knowledge,
\end{abstract}

1 Aluna de graduação em Administração pela FESCG.

2 Doutorando em Administração pela ESAN/UFMS - Professor ESAN/UFMS e FESCG.

3 Doutoranda em Administração pela ESAN/UFMS - Professora ESAN/UFMS e UNIGRAN Campo Grande/MS.

4 Doutorando em Administração pela ESAN/UFMS - Professor Assistente CPTL/UFMS. 
in addition to highlighting the lack of conflicts arising from differences between family and non-family management that coexist in the same business environment.

Keywords: Family Business; Management; Management Challenges.

\section{INTRODUÇÃO}

As empresas estão sujeitas as ameaças e as constantes transformações em seu ambiente empresarial, no que diz respeito às alterações na legislação, concorrência, dos clientes, além das crises econômicas que influenciam no modo de operar. Em um mercado competitivo e de nível mundial leva a família enquanto acionista a ter vantagem competitiva, uma vez que pode contribuir para a estabilização da estratégia e também para a gestão dos recursos disponíveis. É importante que nesse contexto os aspectos emocionais sejam evitados para que não haja interferência na gestão (CUNHA et. al., 2017).

Antigas histórias e dinâmicas familiares podem se intrometer nos relacionamentos de negócios. Pode ser mais difícil exercer autoridade com os parentes. Os papéis na família e na empresa podem tornar-se confusos.

As pressóes da empresa podem sobrecarregar e destruir relacionamentos familiares. Quando o trabalho perde em eficiência, criam-se níveis de tensão, raiva, confusão e desespero que são capazes destruir, de forma surpreendentemente rápida, boas empresas e famílias sadias.

Desta forma, o presente artigo trata da seguinte pergunta de pesquisa: Como se caracteriza a gestão de uma empresa familiar? Sendo o objetivo geral: analisar a gestão de uma empresa familiar sob a ótica de bases conceituais presentes na literatura.

Os objetivos específicos da pesquisa são: apresentar as bases conceituais acerca das questôes mais relevantes da gestão de uma empresa familiar; descrever a empresa familiar Construtelhas Comércio e Serviços Ltda, objeto de estudo, com foco em sua estrutura de gestão e por fim, analisar as práticas e políticas adotadas pela empresa.

Para o desenvolvimento dos pesquisa são analisadas as práticas e políticas adotadas pela empresa objeto do estudo de acordo com as bases conceituais apresentadas no referencial teórico. A conclusão da pesquisa se dá pela reflexão das relações encontradas e da sua contribuição para o mercado como um todo.

\section{REFERENCIAL TEÓRICO}

\subsection{A gestão de empresas familiares}

As empresas familiares são definidas para Perobelli e Fama (2003), como uma estrutura de capital próprio, que financia os ativos e proporciona investimentos para o desenvolvimento de suas atividades.

As empresas familiares são uma parte forte no mercado atual de negócios e podem ser iniciadas, por exemplo, com a reuniáo familiar, onde se decide abrir a empresa. Neste 
momento pode ser tomada a decisão sobre o montante de capital necessário e pode haver um empreendedor e tem o perfil de líder que pode fazer o papel de fundador.

Empresa familiar, para Martins, Menezes e Bernhoeft (1999, p. 33) é "aquela em que um ou mais membros exercem considerável controle administrativo sobre a empresa, por possuir parcela expressiva da propriedade do capital”.

Existe uma relação direta entre propriedade e controle, sendo que o controle é exercido com base na propriedade. Assim, existe uma estrutura gerencial na qual os cargoschave são preenchidos por membros da família (MARTINS; MENEZES; BERNHOEFF, 1999).

Ainda de acordo com Martins, Menezes e Bernhoeft (1999), as empresas familiares podem ser identificadas em dois grupos distintos. O primeiro grupo corresponde às empresas de pequeno e médio porte, de capital fechado, com a propriedade e o controle concentrados na família, ou seja, um ou mais membros da família que ocupam os cargos mais importantes na administração do negócio. Já o segundo grupo é formado pelas empresas de maior porte, com abertura de capital, profissionalização da gestão, descentralização do controle e menor participação de familiares no quadro administrativo (MARTINS; MENEZES; BERNHOEFT, 1999).

Observa-se na origem da empresa familiar um empreendedor nato que inicia a empresa com o auxílio da própria família e alguns funcionários, existindo forte coesão entre estes, trabalho intenso, atenção à produção e venda em detrimento dos controles financeiros e administrativos, conforme ressalta Amendolara (1995).

À medida que o negócio formado pelo empreendedor nato cresce, sua organizaçáo e o padrão gerencial mudam. A gestão, então, precisa se adaptar ao crescimento e à mudança de patamar da empresa, chamados "estágios de crescimento" por Longenecker, Moore e Petty (1997, p. 421), que são: estágio 1, operação de uma pessoa. No estágio 2 aparece a figura do Treinador, no estágio 3 existe a supervisão intermediária e o estágio 4, a organização formal.

As empresas familiares apresentam a sobreposição de três ativos: família, patrimônio e empresa, comprometendo os resultados e colocando em risco a própria permanência no mercado. Para evitar o fechamento destas, é inevitável que desenvolvam processos estruturados de sucessão e governança corporativa, destacando-se a necessidade de reconhecer e aproveitar os valores da empresa familiar, e ao mesmo tempo, saber renová-los. Para tanto, requer-se a presença de um agente renovador, que pode estar presente na geração mais nova da família (AMCHAM BRASIL, 2011).

A profissionalização das empresas familiares, tanto na ótica da propriedade quanto da gestão, é um processo que organiza e atenua o impacto dos aspectos peculiares dessas organizaçóes que dificultam não só sua competitividade, mas também a sua própria sobrevivência. Se precisasse escolher até cinco pontos-chave relacionados com a continuidade das empresas familiares ao longo do tempo, certamente estaria entre eles a profissionalizaçáo (CASILLAS et al., 2007).

No Brasil, existem entre 6 a 8 milhões de empresas, sendo $90 \%$ delas empresas familiares. Seja grande, média ou pequena, as empresas familiares têm um papel significativo no desenvolvimento econômico, social e até político de vários países (SEBRAE, 2016). 
O lucros e o sucesso importam em grande parte para as empresas familiares (JUSTE, 2004), no entanto, grande importância deve ser atribuída à continuidade do negócio da família, que não findará com a morte de seu fundador, tendo continuidade com os outros membros da família, portanto haverá a perpetuação do ramo de negócios.

Conforme Gersick et. al. (1997), através da perspectiva da propriedade, família e gestão/empresa, podem ser identificados sete setores nos quais se inserem os elementos de uma organização familiar de acordo com sua classificação. Os quais sejam: setor 1 Membro da família; setor 2 - acionista que não é membro da família e nem funcionário; setor 3 - funcionário que não é proprietário e nem membro da família; setor 4 - proprietário que é membro da família, mas não trabalha na empresa; setor 5 - proprietário que trabalha na empresa, mas não é membro da família; setor 6 - membro da família, que é funcionário, mas não é proprietário; setor 7 - proprietário que é membro da família e trabalha na empresa (Figura 1).

Figura 1: O Modelo dos Três Círculos.

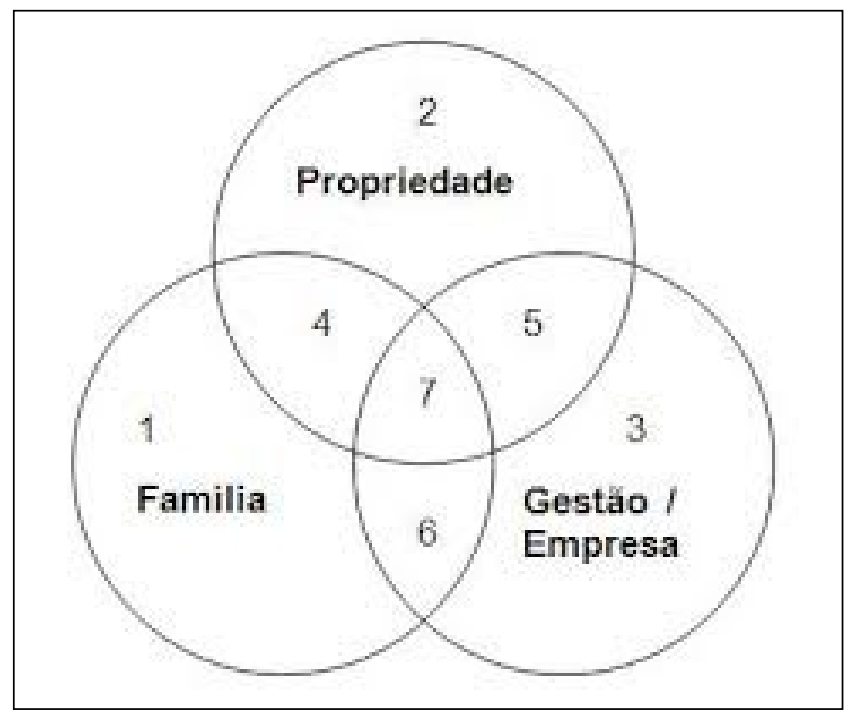

Fonte: Adaptado de Gersick et al (1997)

A gestão de empresas familiares, segundo Maximiano (2000), é voltada para os objetivos da empresa e da família, gerenciamento das funçōes e verificação das funcionalidades das empresas. Os três eixos que constituem família - empresa - patrimônio podem ser caracterizados em um modelo tridimensional (Figura 2). De acordo com as mudanças da empresa familiar, o modelo assume um novo formato e com novos perfis (GERSICK et al, 1997).

A coexistência e a interação das três esferas que compóem a sociedade familiar família, patrimônio e empresa - fazem com que a sua dinâmica envolva questôes de ordem emocional, legal, patrimonial e empresarial (PASSOS, 2006, p.30). 
Conforme Gersick et al (1997), para cada um dos três subsistemas existe uma dimensão de desenvolvimento correspondente, seguindo uma sequência, conforme fica evidenciado na Figura 2.

Figura 2: Modelo Tridimensional de Desenvolvimento da Empresa Familiar

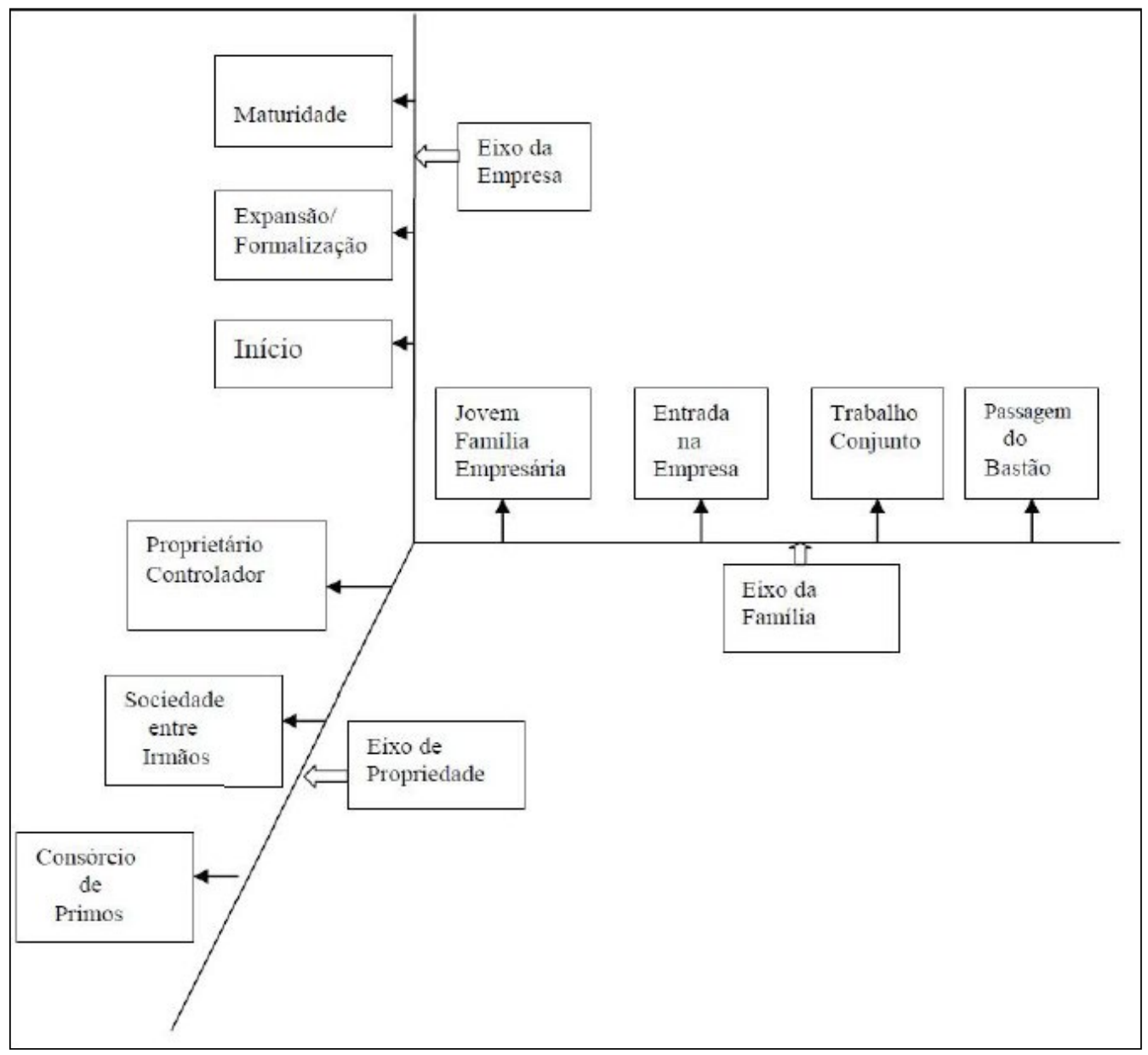

Fonte: Adaptado de Gersick et al. (1997).

Quando o modelo de Gersick et. al. (1997) descreve sobre o eixo da empresa, a dimensão desenvolvimento da propriedade define se determinada organização é de origem familiar ou não.

A propriedade de uma empresa familiar pode recair apenas sobre o proprietário controlador ou sobre irmãos. A progressão de um tipo para outro é considerada desenvolvimentista, pois segue uma seqüência previsível e é, ao menos em parte, motivada pelo envelhecimento e pela expansão da família proprietária. A seqüência de estágios não ocorre de forma rígida, como acontece no desenvolvimento biológico, ou seja, a empresa nasce e cresce e ocorrem os estágios numerados como 1 (família), 3 (gestáo) e 2 (propriedade) 
em primeiro momento. Após esse estágio desenvolvem-se as etapas de número 4, 6 e 5, que correspondem às ligaçóes entre os três primeiros números, para então acontecer a ligação final, número 7. Logo após pode-se dizer que a empresa amadurece, envelhece e morre.

Segundo Gersick et. al. (1997), a dimensão de desenvolvimento da família se aproxima do processo que ocorre com as famílias anos após anos. Elas seguem o ritmo natural da vida humana. Cada novo núcleo familiar é formado nos primeiros anos de vida adulta dos seus membros. Quando estes atingem a meia idade, ela cresce e opera de forma diversificada e, à medida que eles envelhecem e morrem, é lançada uma nova geração. A continuidade da existência humana é realizada por filhos, que amadurecem e tornam-se pais, dando início ao novo ciclo. Essa dimensão é formada por quatro períodos, como no exemplo da empresa em estudo: uma jovem empresária e sua mãe que não trabalha na gestão da empresa, assume a empresa familiar, como um trabalho em conjunto, onde indiretamente ocorre a transferência efetiva do poder de mãe para filha.

Este autor descreve que com relação ao eixo empresa, esta se constitui em três fases.

- Início: está relacionada com o começo da vida da empresa, a qual é composta por duas etapas: formação e sobrevivência. Este período pelo fato da organização ser apenas uma idéia que será realizada e exigirá muitos esforços por parte dos empreendedores.

- Expansão ou formalização: tem o tempo de duração muito relativo, pois depende do tipo de produto ou serviço que é comercializado.

- Maturidade: é o período em que a estrutura organizacional e os principais produtos passam a ter uma evolução mais lenta. As empresas enfrentam um grande dilema que se relaciona com a renovação ou a dissolução da firma, pois ou se adapta às novas exigências do mercado ou o melhor é deixar de atuar dentro dele.

Para Oliveira (2006), o sistema empresa também é considerado um sistema de atividades sociais, porém, os recursos e as obrigaçóes são utilizados para promover a realização dos propósitos organizacionais utilizando-se igualmente de recursos e transaçóes interpessoais.

O sucesso das empresas familiares está ligado aos vários estágios da sua vida e gestão, tais como: a propriedade/gestão; continuidade/sucessão; acesso/ utilização do capital e gestão de recursos humanos. Este sucesso, muitas vezes está intimamente ligado à ação dos seus fundadores, que nem sempre conseguem tomar todas as decisóes corretas em todas as vertentes (OLIVEIRA, 2006).

Em relação aos fundadores das empresas familiares, estes nem sempre são bons membros da organização, pois, embora sendo criativos e inovadores, podem apresentar dificuldades para atuar em organizaçóes com gestão formal e como consequência, ignorar o valor de uma gestão profissionalizada (LONGENECKER; MOORE; PETTY, 1997). Neste sentido, para Longenecker, Moore e Petty (1997), o desafio dos fundadores é que acrescentam gerenciamento profissional em seu negócio sem sacrificar o espírito empreendedor que os caracterizam e os valores que influenciaram na conquista de um início bem sucedido. 


\subsection{Desafios e tendências}

Desafios surgem no caminho das empresas familiares, exigindo muitas vezes mudanças radicais em suas estratégias. Segundo Martins, Menezes e Bernhoeft (1999) diversas empresas familiares não resistem às dificuldades que se apresentam e perdem o controle sobre a gestão, ocasionado por fatores externos e internos ao empreendimento. Dentre os quais: a globalização da economia e do mercado mundial; a estabilidade da economia (necessidade de ajustar os preços de acordo com o poder aquisitivo do cliente); a inadaptabilidade dos herdeiros ao fim da era de maiores lucros grandes e a riqueza muda de mãos.

Em relação às tendências envolvendo as empresas familiares, Martins, Menezes e Bernhoeft (1999) assinalam que um dos instrumentos considerado útil é a criação de conselhos, que podem dar início ao processo de separação entre o que é administrativo e a propriedade, e a gestão executiva das atividades do próprio negócio. Os autores lembram ainda que a condição de conselheiro traz consigo deveres e responsabilidades, na forma prevista em lei (Lei 6.404, de 15 de Dezembro de 1976, Lei das Sociedades por Açóes).

Um gerenciamento mais eficaz torna-se necessário à medida que o negócio se expande. Empresas com estrutura gerencial restrita podem até sobreviver no mercado em que atuam em funçáo da qualidade de seus produtos ou serviços, compensando assim as deficiências na sua gestão. Além disso, as dificuldades no gerenciamento impóem conflitos e retardam o seu desenvolvimento (LONGENECKER; MOORE; PETTY, 1997).

Martins (2014) argumenta que especialistas ajudam no diagnóstico, sugerindo, por exemplo: cláusulas peculiares a cada situação, como ingresso de novos sócios, alguma restrição aos poderes dos acionistas, ou a formação de holding. Esta última tem sido uma forte tendência, uma vez que sua implantação pode minimizar potenciais conflitos e garantir benefícios fiscais no momento da sucessão. Neste âmbito, a governança corporativa também pode ser considerada outra tendência importante, à medida que a transparência está entre um dos seus princípios.

Frente a tais desafios, um modelo eficaz de gestão é aquele baseado em dois princípios: Meritocracia (pessoas) e Melhora Contínua (processos). Com base nesse, é possível caminhar a um crescimento sustentável (MARTINS, 2014).

\subsection{A profissionalização nas empresas familiares}

No contexto econômico globalizado a empresa familiar se vê forçada a ajustar-se aos novos paradigmas, buscando acompanhar as rápidas mudanças do mercado e competir com estrutura profissional, distante de disputas de poder ou acomodamento de familiares em cargos-chave apenas porque ostentam o sobrenome da família (FLORIANI, 2002).

Floriani (2002) ressalta que liderança e profissionalização são atualmente os pontos decisivos na estrutura da empresa familiar, no sentido de potencializar a perspectiva de prosperar, sem que sofra dificuldades de gestão a cada momento da "passagem do bastão" de uma geraçáo para a seguinte. 
Neste sentido, conforme Bernhoeft (1991, p. 44), duas questōes devem ser consideradas. Primeira, "profissionalizar a empresa não significa retirar o controle familiar e simplesmente entregá-lo a um grupo de executivos contratados externamente". A segunda é que "a empresa familiar é viável como tal, e o seu processo de profissionalização deve ser feito de dentro para fora, ou seja, envolvendo todas as partes comprometidas"

O gestor, herdeiro ou não, antes de iniciar seu trabalho de profissionalização na empresa familiar precisa ser capaz de responder algumas questóes-chave, de sua própria sobrevivência, conforme Lodi (1997, p. 80):

[...] Quem manda de fato nessa empresa? O que ele quer? Quem o apoia? Que grau de força ele tem? O que ocorrerá com as partes contrárias? Qual o custo político se quem manda decidir se unir com a oposição?

Para Bernhoeft (1991, p. 118) deve-se olhar a organização como um sistema, pois "esta visão nos permite compreender alguns fenômenos que não podem ser desprezados, sempre que se deseja realizar algum processo de intervenção organizacional". Para tanto, a empresa pode ser dividida em três subsistemas:

\begin{abstract}
a) subsistema social: aquele que envolve a cultura na organização, seus valores, clima organização, jogos de poder, hábitos e costumes, identidade organizacional, entre outros aspectos; b) subsistema técnico: refere-se à estrutura organizacional formal, às normas e procedimentos, às instalações, equipamentos, métodos de trabalho, procedimentos administrativos, níveis formalizados de responsabilidades e autoridade, entre outros; c) subsistema gerencial: envolve comportamento e postura do grupo executivo, abrangendo a visão organizacional, integração horizontal/vertical e habilidades gerenciais (BERNHOEFT, 1991, p. 118).
\end{abstract}

O autor salienta que os três subsistemas se encontram interligados e têm a finalidade de facilitar o processo de intervenção organizacional (controle).

Lodi (1997) destaca, entre outras, as funçóes de planejamento e controle do grupo gerencial nas áreas de finanças, novos investimentos e desenvolvimento, serviços técnicos e consultoria jurídica. Fica ainda a cargo desta, decidir pela prestação de serviços às empresas controladas em relação à implantação de sistemas e computação, aluguel de máquinas e equipamentos, organizaçáo, pessoal e gestáo.

Floriani (2002) cita que a Comissão de Valores Mobiliários (CVM) enfatiza que o Conselho de Administração, Conselho Fiscal e Auditoria Independente são recursos que as empresas familiares podem utilizar para melhor identificar o grau de profissionalizaçáo e melhorar a qualidade dos investimentos.

\title{
2.4 O processo de sucessáo
}

Martins (2014, s.p) descreve que passar o bastão para os sucessores é um dos grandes desafios das empresas familiares, pois se trata de uma questão que envolve, direta ou indiretamente, todos os membros da família, afetados pelo êxito ou fracasso do proprietário fundador da empresa (MARTINS, 2014), sendo importante iniciar o planejamento sucessório mesmo com o fundador ainda no comando (COHN, 1991, p. 5). 
No período que antecede a sucessão surgem diversos questionamentos, tais como: quais qualidades de liderança e desempenho meu sucessor deve possuir para garantir a sobrevivência e rentabilidade da empresa? Quais são as opçóes que devo fazer agora a fim de promover a sucessão da liderança que deixará minha empresa operar com lucro por outras geraçóes? (COHN, 1991).

As respostas a esses questionamentos podem dar origem ao plano de sucessão na empresa familiar, identificando-se as atividades gerenciais de planejamento, exercício da liderança, organização e controle. Caso o plano de sucessão seja mal elaborado e encaminhado, poderá resultar em conflitos e até na venda da empresa (MARTINS; MENEZES; BERNHOEFT, 1999).

Para Freire et al. (2010) a sucessão na gestão é vista como processo de mudanças, primeiro passo para a diminuição de erros e conflitos, tanto para os líderes quanto para os funcionários e colaboradores, e essa sucessão é vista como "um processo de oxigenação da gestáo", pressupondo a definição de caminhos que possam minimizar os efeitos das resistências individuais que o processo de sucessão promove na organização. Para os autores, essa resistência individual às mudanças é provocada pela "resistência em sair da zona de conforto", identificada por eles como "respostas programadas e sensação de segurança que as rotinas transmitem".

\section{Metodologia}

Trata-se de uma pesquisa de cunho exploratório-descritivo (ANDRADE, 2003; SELLTIZ et al., 1975), originada de um estudo de caso (VERGARA, 2003), da empresa familiar denominada Construtelhas Comércio e Serviços Ltda, CNPJ 13.170.943/000104, criada em 28/01/2011 no ramo do Comércio atacadista especializado em materiais de construção, como: cal, areia, pedra britada, tijolos e telhas, além de transporte rodoviário de carga, exceto produtos perigosos e mudanças, intermunicipal, interestadual e internacional, localizada em Campo Grande-MS.

Para Vergara (2003, p. 49), “o estudo de caso é o circunscrito a uma ou poucas unidades, entendidas essas como pessoa, família, produto, empresa, órgão público, comunidade ou mesmo país". É denominada de cunho exploratório por buscar descobrir maiores informações sobre determinado assunto, facilitando a compreensão do tema pesquisado e a confirmaçáo de teorias existentes e amplamente aceitas. E, tem caráter descritivo por observar, registrar e analisar fenômenos e fatos da realidade sem manipulá-los (SELLTIZ et al., 1975).

A pesquisa se iniciou com o levantamento bibliográfico sobre o tema, que consistiu em uma fonte de dados secundários, onde houve a exploraçáo de artigos, livros, com o intuito de obter maior conhecimento sobre o tema, servindo de base para elaboração da análise.

Como técnica para a coleta de dados, utilizou-se de observação e interrogação, além de um roteiro de entrevista direcionado ao gestor da empresa, pautada nos pontos fundamentais identificados através da pesquisa bibliográfica acerca da literatura sobre o tema. 
Como técnica para análise dos dados, utilizou-se da Análise de Conteúdo, que segundo Chizzotti (2006, p. 98) "é uma técnica para ler e interpretar conteúdo de todos os documentos, com objetivo de compreender criticamente o sentido das comunicaçóes, seu conteúdo manifesto ou latente, as significaçóes explícitas ou ocultas".

\section{Resultados e discussáo}

\subsection{Apresentaçáo da empresa}

A empresa Construtelhas Comércio e Serviços Ltda estabelecida no município de Campo Grande-MS iniciou suas atividades em janeiro de 2011. Constituída pela sociedade de cotas por responsabilidade limitada até hoje formada por mãe e filha.

A atual gestora da empresa, enquanto cursava faculdade, no ano de 2009 era estagiária em uma empresa que comercializava produtos para construção civil. Após concluir sua formação, no ano de 2010, em função de sua experiência no estágio e visão, percebeu que o setor da construção civil estava em ascensão, enxergando uma oportunidade de negócio. Decidiu entáo que abriria uma empresa de materiais de construçáo e contou com a ajuda de sua mãe, a qual é sócia na empresa.

Dessa forma, a empresa Construtelhas Comércio e Serviços Ltda foi criada em janeiro de 2011. A composição inicial da empresa era a mãe, a filha, que são sócias na empresa e uma prima que fazia a parte administrativa. Sua característica comercial é comprovada através de suas práticas de comercializaçáo de cal, areia, pedra britada, tijolos e telhas. Também possui como outro objetivo social a prestação de serviços.

Contudo, a partir do crescimento das vendas, foi necessária a contratação de mais funcionários. Desde Janeiro de 2012, a empresa conta com um quadro de 6 funcionários, sendo dois vendedores, um motorista de caminhão, dois ajudantes de pátio e uma funcionária da área administrativa. Salienta-se ainda que a empresa se encontra na primeira geração.

Quanto à missão, visão e valores, segundo a proprietária a missão é satisfazer os clientes com produtos de qualidade, rapidez na entrega e ótimo atendimento. Acredita ser muito importante para a empresa para que todos possam saber como é, e onde a empresa quer chegar.

Neste sentido, para Certo (2006, p. 49) missão é "uma proposta da razão pela qual a organização existe. Apresenta informaçôes sobre tipos de produto ou serviço que a empresa oferece; quem são seus clientes e que valores importantes possuem".

Através da missão da empresa sabemos a necessidade básica que a organização pretende suprir, e a importância do seu papel no mundo externo. Quanto à visão e valores, devem ser definidas de maneira simples, objetiva, mas compreensível a todos, devendo ser compartilhada pelas pessoas que formam o corpo dirigente da empresa, bem como explicada, justificada e disseminada por todos os que trabalham para a organização (COSTA, 2010). 


\subsubsection{Organograma da empresa}

A partir do relato da proprietária pôde ser elaborado o seguinte organograma da estrutura organizacional (Figura 3), a qual, não se encontrava documentada ou formalizada na empresa.

Figura 3 - Organograma da empresa

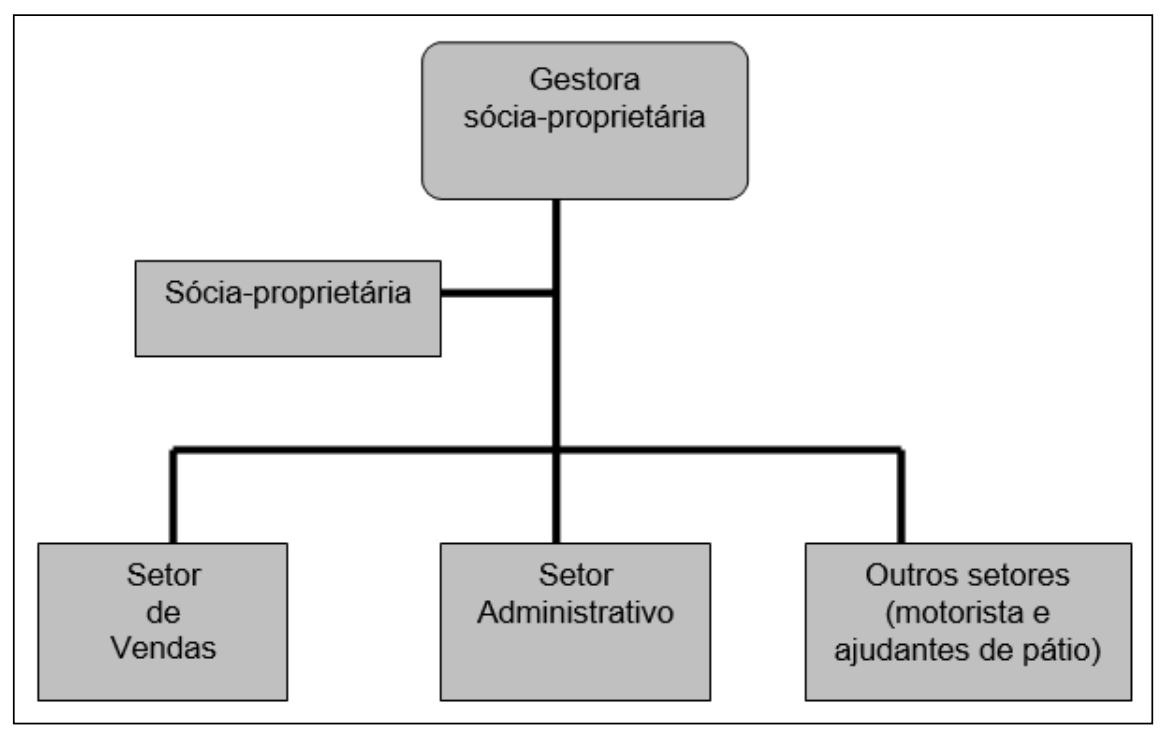

Fonte: Elaborado pelos autores.

A gestora da empresa é responsável pela administração, pela gerência e também tem todo controle de vendas e finanças.

O setor de vendas conta com dois funcionários que atendem clientes, tanto no balcão quanto via ligação telefônica e em visitas a obras.

Outros setores contam com o motorista do caminháo que transporta os materiais para a entrega aos clientes, e os ajudantes de pátio que carregam o caminhão com os materiais e descarregam no endereço do cliente.

Inicialmente se manteve a gestão da empresa nas mãos das sócias (mãe e filha). No entanto, hoje a mãe não trabalha mais na empresa, fazendo somente a parte de contadora, quando é solicitada. Um serviço à parte. Atualmente toda coordenação e supervisão dos produtos concentra-se apenas na proprietária gestora (filha), a qual pode ser considerada uma proprietária-controladora, por centralizar em si grande parte das decisôes relacionadas à empresa. A gestora desenvolveu um ambiente paternalista, tratando a empresa como uma família, buscando a harmonia e o comprometimento de todos os seus membros. 


\subsection{Os elementos e o desenvolvimento tridimensional da empresa}

A empresa estudada tem 5 anos de existência no mercado, a gestora conta com o apoio de sua mãe, que por ser contadora, auxilia principalmente na contabilidade da mesma quando necessário.

Sociedade Limitada, nesse tipo de empresa duas ou mais pessoas associam-se para a criação de uma pessoa jurídica, com existência e patrimônio distintos da pessoa física dos sócios. Quem exerce a atividade empresarial é a sociedade (representada pelos seus administradores), e quem responde pelas dívidas contraídas é o patrimônio da sociedade. Em síntese, a responsabilidade dos sócios é limitada.

É importante salientar que havendo indícios de abuso ou confusão patrimonial, a personalidade jurídica pode ser desconsiderada, respondendo então os sócios e administradores pelos débitos.

$\mathrm{Na}$ dimensão de desenvolvimento da propriedade, o modelo mostra seus estágios e as possíveis mutaçóes ao longo do tempo. Gersick et al. (1997) trabalha essa dimensão com o pressuposto de que as diferentes formas de propriedade da família resultam em diferenças fundamentais em todos os aspectos da empresa familiar. Algumas são de propriedade de uma só pessoa, ou de um casal, ou de dois sócios sem relação de parentesco. No outro extremo da escala de complexidade, estão as empresas de propriedade de combinaçóes de membros de uma família (chegando, em alguns casos, às centenas), acionistas públicos, fundos e outras empresas. Os autores atentam que nem sempre o desenvolvimento dessa dimensão segue essa cronologia e pode ser afetada por mudanças em seu controle acionário, assumindo uma direção desenvolvimentista subjacente.

Álvares et al. (2003) faz uma análise sobre o relacionamento entre os três subsistemas propostos por Gersick et al. (1997): propriedade, família e empresa.

A partir da análise realizada na empresa em estudo, buscamos aqui inseri-la no modelo de três círculos. Onde pode se alocar membros em dois setores dos sete existentes no modelo, conforme Figura 1 acima.

Unindo a pesquisa in loco e a teoria de Gersick et. al. (1997), a empresa pode ser distribuída da seguinte forma: no setor 1, como membro da família, a mãe sócia-proprietária, a filha proprietária gestora da empresa e a prima que auxilia na parte administrativa. Já o setor 2, acionista que não é membro da família e nem funcionário, não existe na empresa estudada, portanto não cabe compará-lo com o modelo dos três círculos. Setor 3, como funcionários, que não são proprietários nem membros da família, incluem-se os 5 funcionários da empresa, isto é, a força de trabalho contratada pela gerência, entre eles estão vendedores, ajudantes de pátio e motorista de caminhão. Referente ao setor 4, tendo proprietários, que são membros da família, mas não trabalham na empresa; encontram-se a sócia-proprietária (mãe da gestora). Em seguida no setor 5 , onde estão os proprietários que trabalham na empresa, mas não são membros da família, não incluem nenhum participante, nesta empresa pesquisada, pois é lema da empresa não ter na direção ou gerência, pessoa que não seja membro da família. O setor 6 , envolve membros da família, que são funcionários, mas não são proprietários, identificando-se na empresa Construtelhas Comércio e Serviço Ltda como pertencente a este setor a prima que dá suporte na área administrativa. Por fim, 
no setor 7, apresenta-se a proprietária, que é membro da família e trabalha na empresa, a qual atualmente opera na empresa como única gestora.

Há aqui um enfoque no grau de sobreposição em que os três círculos se expõem. O impacto dessa sobreposição, maior ou menor, na família e na empresa, é determinado pelo grau em que ela ocorre.

$\mathrm{Na}$ empresa pesquisada, há o entrelaçamento da família e empresa, mas preservando a individualidade, ao lado da individualidade da família que a controla ou administra. Para Álvares et. al. (2003), os diferentes graus de sobreposição podem ser descritos como segue:

Figura 4 - Grau de sobreposição do sistema família/propriedade/empresa

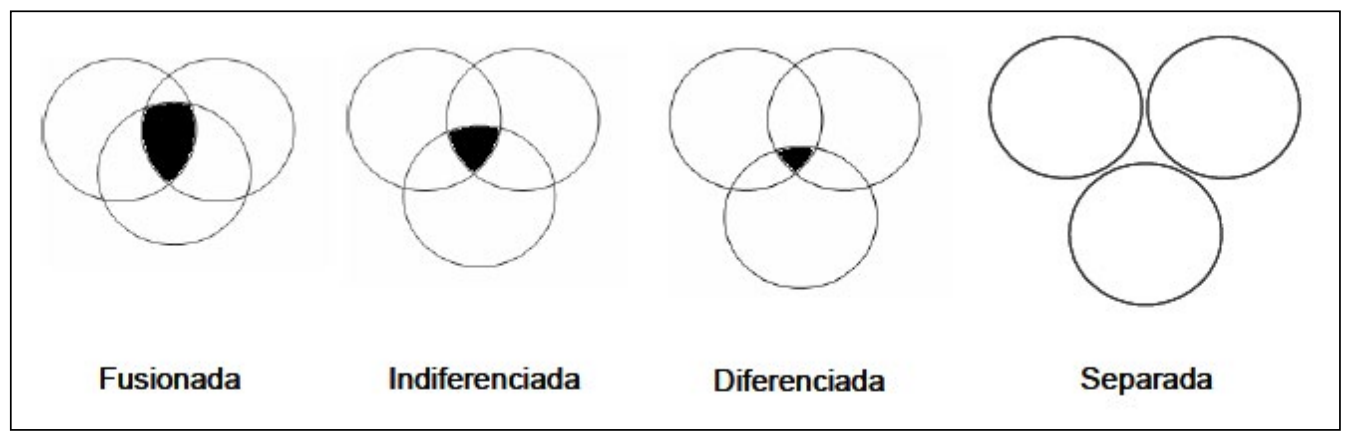

Fonte: Adaptado de Álvares et. al., 2003.

No Modelo Fusionada, a empresa tem seus sistemas fortemente superpostos, exemplo da empresa pesquisada, onde membro da família ocupa todos os cargos de direçáo e cargos de gerência. $\mathrm{O}$ capital é todo familiar, podendo o patrimônio da empresa ser confundido com o da família; os interesses da família se confundem ou são mais importantes do que os objetivos da empresa; a gestora orquestra tudo e toma todas as decisóes.

Ricca (2007), cita que é comum encontrar empresas familiares com graus de sobreposição de papéis, o favoritismo, o excesso de controle, confiança e de segredos, envolvendo tanto os diversos grupos familiares quanto os profissionais com quem trabalham mais diretamente.

Um resultado disso é a ausência de qualquer conceito de governança corporativa, com uma mentalidade totalmente distorcida e não direcionada a resultados efetivos, do ponto de vista empresarial. A consequência disso é a dificuldade crescente para atrair profissionais e talentos, de manter um nível adequado de investimento no negócio, a dilapidação indireta do patrimônio e a perda da visão estratégica (RICCA, 2007).

$\mathrm{Na}$ Indiferenciada, a empresa tem em seus sistemas uma sobreposição significativa, que é administrador profissional que não pertence à família é expressiva, mas os interesses e a influência da família sobre a organização também são grandes; a identidade da empresa confunde-se com a da família. Não cabe aqui na empresa pesquisada esta sobreposição.

No terceiro, que é a Diferenciada, a empresa e família têm identidades próprias: a família pode ter controle acionário, mas há separação entre os interesses da empresa e 
da família, que tem comprometimento com o capital. Os acionistas entendem que uma empresa bem-sucedida assegura os interesses de longo prazo da família; o poder decisório é compartilhado; o sistema é aberto. Neste exemplo, existe boa governança, entendimentos que são elaborados ao longo da existência da sociedade, estabelecendo padróes de diferenciação entre família; empresa e propriedade. Aqui a empresa pesquisada faz essa separaçáo e os conflitos são tratados no plano mais racional.

Na sobreposição denominada de Separada, o qual o próprio nome já dá o significado, há uma completa separação entre família, empresa e capital. Nesse caso, deixa de ser familiar. Usa-se esse recurso para eliminar ou reduzir problema, eliminando-se, assim, a figura da empresa familiar, que só existe enquanto vinculada a uma ou mais famílias.

À gestora da empresa cabe a administração com poderes e atribuiçóes de administrador, autorizado o uso do nome empresarial, vedado, no entanto, em atividades estranhas ao interesse social ou assumir obrigaçóes seja em favor de qualquer dos quotistas ou de terceiros, bem como onerar ou alienar bem imóveis da sociedade, sem autorizaçáo do outro sócio.

A Construtelhas conta com Transportes Dandolini, Transcargueiro. São empresas que fazem o transporte do material que vem de Sangão - SC e Itu - SP, como parceiros. A empresa está bem localizada à Avenida Salgado Filho, Vila Progresso em Campo GrandeMS, trabalhando com telhas, cimento e todos os materiais de construção e hidráulica. Destaca-se da concorrência pelos horários e dias da semana que atendem ao público.

Com embasamento na teoria demonstrada na literatura exposta anteriormente, têmse o modelo tridimensional, que insere o desenvolvimento ao longo do tempo aos três círculos, apresentando assim, por meio deste modelo, como se dá o desenvolvimento da empresa familiar de forma dinâmica. Estudo que foi desenvolvido por Gersick et al. (1997) e será aplicado a realidade da empresa.

Iniciando a análise da empresa sob o eixo do Desenvolvimento da Propriedade, sendo esta que define a empresa familiar, em que na empresa pesquisada uma das sócias cursou na faculdade Fatec Senai o curso de Tecnologia em processo gerencial com período de 18 meses, resolveu entáo, junto com a mãe, criar uma sociedade e iniciar uma empresa no ramo da construção civil, onde vende produtos como: telhas, cimento, prego, etc.

Mãe e filha tinham um capital inicial, o que facilitou o fortalecimento da empresa, já que não tinham dívidas bancárias para pagar. Em relação ainda a esse desafio inicial, vale lembrar que mesmo com o financiamento de terceiros (bancos), estes não passaram a ter parte da propriedade da empresa, evitando assim o controle e interferência na gestáo da empresa por parte de outras pessoas. No controle concentra-se atualmente apenas na proprietária gestora, a qual pode ser considera uma proprietária-controladora, por centralizar grande parte das decisões relacionadas à empresa.

Por ser uma empresa com apenas dois ramos familiares e uma prima, há uma menor complexidade entre família/empresa. Ambas as sócias tem a função de buscar equilibrar o papel empresarial e familiar.

Quanto à passagem do bastão, mostra-se como um grande desafio para a gestora, em entrevista esta relata que não pensaram nessa possibilidade, até porque a empresa é nova, 
está em crescimento e segundo a mãe da gestora, esse assunto poderá ser discutido em breve, somente como uma prevenção, pois ainda não teriam nem quem indicar a este cargo.

Por fim, Gersick et al. (1997) apresenta o eixo de Desenvolvimento da Empresa, onde por meio das medidas de crescimento e de complexidade insere as empresas familiares em seus estágios. A empresa Construtelhas Comércio e Serviços Ltda encontra-se no estágio de formalização, pois busca o equilíbrio entre as finanças da família e da empresa, e que tem como norma evitar grandes retiradas, a não ser em forma de pró-labore, para que a empresa não sofra quedas em seu setor financeiro. Conforme a Sócia-proprietária afirma, a empresa sempre precisa ter reservas em caixa para possíveis problemas e também como uma das metas fazer reinvestimentos de capital e de continuidade da empresa.

\subsection{Profissionalizaçáo}

Como se sabe, nesse processo, os esforços organizacionais adotados pela administração vão se formalizando à medida que a empresa vai passando pelas diferentes fases de seu crescimento. De forma mais específica, a profissionalização se apoia em duas grandes frentes de ação: o processo de delegação de responsabilidade e o grau de formalização dos mecanismos utilizados para o controle das açóes dentro da organização.

Citou-se delegação de responsabilidade, como foco na empresa pesquisada, onde aparece a gestora como líder no processo de transferência de deveres e responsabilidade aos seus subordinados.

Já com relação ao grau de formalização a empresa em questão documenta e padroniza os processos e procedimentos, principalmente quando se trata de capacitação de profissionais, investindo em seus funcionários, os vendedores da empresa fazem cursos de reciclagem pelo menos uma vez por ano.

A gestora acredita que a profissionalização é o caminho para o sucesso em uma empresa familiar até mesmo porque foi em um período de uma profissionalização de uma das sócias que se teve a ideia de abrir a loja. Também possui conhecimento na área comercial, pois já trabalhou com vendas e atendimento ao publico durante algum tempo em outra empresa como supervisora administrativa e financeira, facilitando sua posiçáo diante de seus clientes.

Padula (2002) ainda orienta que o empresário deve, primeiramente, reconhecer e convencer-se da necessidade de tais mudanças. Ele deve estabelecer e implantar um programa de açóes para facilitar o processo de mudanças profundas que a profissionalização implica. A organização de um sistema de gestão dividido em atividades de planejamento, organização e controle de forma integrada e em todos os setores da empresa, serve de orientaçáo para realizar os grandes objetivos organizacionais.

\subsection{Sucessão}

Com relação à sucessão, a proprietária descreve que este assunto é um grande desafio para a empresa, sobretudo no que diz respeito ao desligamento da geração mais velha da empresa, na pessoa da proprietária e considera um dos itens mais importantes nesse processo. 
Segundo a gestora, é necessário elaborar um plano de sucessão, depois estudar outros casos de sucessão bem sucedida, obter aconselhamento jurídico externo e por fim, debater este assunto no conselho familiar.

Para Oliveira (2006), o processo sucessório é um momento importante para otimização da continuidade da empresa e, se esse momento não apresentar os resultados esperados, a efetividade da empresa familiar pode estar bastante comprometida.

Portanto quanto às questóes de sucessão, ficou claro que ainda não pensaram no assunto. Entretanto, a gestora destacou que será trabalhado dentro do processo de governança que iniciará sua implantação no segundo semestre de 2016. A gestora classificou ainda, o processo de sucessão como não sendo um processo fácil de formalizar.

\subsection{Principais dificuldades e perspectivas para o futuro}

Segundo a proprietária, a mistura da relação empresarial e familiar, acaba por interferir negativamente no dia a dia. Isto, à medida que com a centralização na gestão, o "dono" acaba fazendo um pouco de todas as funçôes. Foi salientado também que existe a falta de organização na parte financeira, na qual por muitas vezes acaba por "misturar" o fluxo de caixa da empresa com o pessoal.

Outro ponto abordado no que diz respeito às dificuldades em empresas familiares, a solução de conflitos entre os membros da mesma, a proprietária disse que na empresa a administração fica apenas com uma pessoa, todas as decisóes são tomadas pela administradora, ficando toda responsabilidade do funcionamento da loja à ela. E o sucesso da empresa se deve ao fato da proprietária fazer questáo de acompanhar de perto os fatos mais importantes que acontecem na empresa, e esse modelo inovador de gestáo. Sobre a visão do futuro e seus planejamentos para os próximos anos, a proprietária menciona que atualmente é conforme a economia do país, sendo o planejamento apenas mensal e que também abordará em seu processo de governança uma estratégia empresarial.

Segundo Maximiano (2009, p.15)

a estratégia empresarial é o curso de ação que uma empresa adota para assegurar seus objetivos de desempenho como sua sobrevivência, o tamanho que pretende alcançar, os concorrentes que deseja enfrentar ou a posição que pretende ter no mercado.

Isso se torna particularmente importante nas organizaçóes orientadas por valores porque existem sempre coalizóes de pessoas com aspiraçóes diferentes que precisam ser integradas para que a organização progrida.

\section{Consideraçóes finais}

Neste estudo identifica-se um caso híbrido na forma de gestão da empresa, onde há uma sociedade entre máe e filha, mas somente uma delas atua como gestora, exercendo o papel de proprietária-controladora. Gestora empreendedora, com metas positivas demonstrando comprometimento com os funcionários. 
No quesito sucessão, a empresa se encontra na primeira geração, esse processo não foi discutido ainda, e não possui um plano formalizado e nem informal. Além disso, para a gestora é confuso o entendimento da sucessão da propriedade e da gestáo, não percebendo uma separaçáo entre os processos, apesar disso, pretendem que sua empresa perdure por mais geraçôes. Desta forma, buscou-se expor à sócia a importância e necessidade do processo sucessório, sendo que este é imprescindível para viabilizar a continuidade da empresa.

A empresa tem um acordo de sociedade, onde estabelece os direitos e deveres de cada um, e desta forma possibilitando a administração de conflitos, e evitando retiradas de capital quando náo é de extrema necessidade. Desta forma, em virtude do modelo de gestáo identificado na empresa estudada pode-se afirmar em linhas gerais que a mesma apresentou e ainda apresenta um eficiente gerenciamento dos desafios e características que a diferenciam como empresa familiar.

A Empresa Construtelhas Comércio e Serviços Ltda, apesar de estar há 5 anos no mercado apresenta-se como uma empresa de sucesso e sua sócia proprietária (gestora) vêm tendo êxito com a administração. Apesar de todo sucesso, a organização está passando por um processo de profissionalizaçáo e utilizará mecanismos de governança para apoiar e organizar essa importante etapa de seu desenvolvimento.

A literatura sobre empresa familiar defende que a profissionalizaçáo da gestáo, bem como da propriedade, é uma das principais alternativas para a sobrevivência desse tipo de empresa e auxilia a separação entre propriedade, gestão e família, ponto considerado crucial nesse tipo de empresa, bem como o trabalho no modelo clássico dos Três Círculos já citados nesta pesquisa.

Neste sentido, a proprietária considera como sendo de grande importância, utilizandose desta ferramenta como auxílio ao desenvolvimento e sobrevivência da empresa, trazendo ganhos náo somente para esta como para a família.

Cabe aos membros da família minimizar os conflitos, por meio da comunicação. Por outro lado, percebeu-se que o comprometimento e a união das pessoas de um meio familiar, podem amenizar ameaças e influenciar no sucesso dos negócios.

Os resultados apontados pela empresa estudada mostram que ela não tem problemas sérios quanto às situaçôes familiares e empresariais, no sentido de uma interferir negativamente na outra. No entanto, a gestora por ser ainda muito jovem, não trabalhou o assunto sobre a sua sucessão. Atualmente a empresa encontra-se na sua melhor gestão empresarial, um dos motivos é a formação acadêmica da proprietária e a experiência adquirida com os trabalhos realizados dentro e fora da empresa.

\section{Referências}

ALVARES, Elismar (Org.). Governando a empresa familiar. Rio de Janeiro: Qualitymark; Belo Horizonte: Fundação Dom Cabral, 2003. p. 33, 58, 105, 111.

AMCHAM BRASIL. Profissionalizaçáo da empresa familiar é fundamental para a continuidade no mercado. Gestáo Empresarial. 25 de Outubro de 2011. Disponível em: 
$<$ http://www.amcham.com.br/gestao-empresarial/noticias/profissionalizacao-da-empresafamiliar-e-fundamental-para-continuidade-no-mercado>. Acesso em Março de 2016.

AMENDOLARA, L. Como evitar a guerra da sucessáo: orientaçóes e ideias para realizar a passagem do poder na empresa familiar, de modo racional e seguro. São Paulo: Editora STS, 1995.

ANDRADE, M. M. de Introduçáo à metodologia do trabalho científico: elaboração de trabalhos na graduação. 6. ed. São Paulo; Atlas, 2003.

BERNHOEFT, R. Empresa familiar: sucessão profissionalizada ou sobrevivência comprometida. 2. Ed. São Paulo: Nobel, 1991.

CASILLAS, J. C.; SÁNCHEZ, A. V.; FERNÁNDEZ, C. D. Gestáo da empresa familiar: conceitos, casos e soluçōes. Tradução de Vértice Translate. São Paulo: Thomson Learning, 2007. p. 4, 27-28, 32, 71, 78 e119.

CERTO, S. C. et alli. Administraçáo estratégica. 2. ed. São Paulo: Person, 2006.

CHIZZOTTI, A. Pesquisa em ciências humanas e sociais. 8 ed. São Paulo: Cortez, 2006.

COHN, M. Passando a tocha: como conduzir e resolver os problemas de sucessão familiar. São Paulo: Makron, McGraw-Hill, 1991.

COSTA, E. Gestáo estratégica: da empresa que temos para a empresa que queremos. 2. ed. São Paulo: Saraiva, 2010.

CUNHA, M.; REGO, A.; CUNHA, A.; FERNANDES, F. Como liderar empresas familiares. Alfragide: Lua de Papel, 2017.

FLORIANI, O. P. Empresa familiar ou... inferno familiar? Curitiba: Juruá, 2002.

FREIRE, P. de S.; SOARES, A. P.; NAKAYAMA, M. K.; SPANHOL, F. J. Artigo. Processo de sucessão em empresa familiar: gestáo do conhecimento contornando resistência às mudanças organizacionais. In: JISTEM. Revista de Gestáo da Tecnologia e Sistemas de Informaçáo. Vol. 7, n. 3, 2010, p. 713-736.

GERSICK, K.; DAVIS, J. A.; HAMPTON, M.; McCollon; LANSBERG, I. De geraçáo para geraçáo: ciclos de vida da empresa familiar. Tradução de Nivaldo Montingelli Júnior. 2. ed. São Paulo: Negócio, 1997.

JUSTE. A.D; A empresa familiar, 1 ed.Editoração Preview - artes gráficas. 2004

LONGENECKER, J. G.; MOORE, C. W.; PETTY, J.W. Administraçáo de pequenas empresas. São Paulo: Makron Book, 1997. 
LODI, J. B. Sucessão e conflito na empresa familiar. São Paulo: Pioneira, 1997.

MARTINS, D. Gestão de empresas familiares requer profissionalizaçáo. Disponível em: <http://www.valor.com.br/financas/gestao-de-empresas-familiares-requerprofissionalizacao >. Acesso em Março de 2016.

MARTINS, I. G. da S.; MENEZES, P. L. de; BERNHOEFT, R. (Coordenadores). Empresas familiares brasileiras: perfil e perspectivas. São Paulo: Negócio Editora, 1999.

MAXIMIANO, A.C.A. Introdução à Administração. 7. ed. São Paulo: Atlas, 2009

MAXIMIANO, A.C.A. Teoria Geral da Administraçáo: da escola científica à competitividade na economia globalizada. 2.ed. São Paulo: Atlas, 2000.

OLIVEIRA, Djalma de Pinho Rebouças. Empresa familiar: como fortalecer o empreendimento e otimizar o processo sucessório. 2 ed. São Paulo: Atlas, 2006. p. 11-12, 19, 41, 138-139, 200 e 245.

PADULA, A.D. Empresa familiar: profissionalização, desenvolvimento e sucessão. 2.ed. Porto Alegre: SEBRAE/RS, 2002.

PASSOS, E. Família, negócios à parte: como fortalecer laços e desatar nós na empresa familiar. São Paulo: Gente, 2006.

PEROBELLI, F.C.O.; FAMÁ, R. Fatores determinantes da estrutura de capital para empresas Latino-Americanas. Revista de Administraçáo Contemporânea. Curitiba, 2003.

RICCA, D. Sucessão na empresa familiar: conflitos e soluções. São Paulo: Editora CLA, 2007. p. 86-87.

SEBRAE/SC, Artigos para MPES, No Brasil, 90\% das empresas são familiares. Disponível em: <http://www.sebrae-sc.com.br/newart/default.asp? materia=10410>. Acesso em Março de 2016.

SELLTIZ, C. Métodos de pesquisa nas relaçóes sociais. 2. ed. São Paulo : EDPVEDUSP, 1975. 